finds weaknesses in administration and procedures which it is able to eliminate; it receives suggestions from men whose views have not previously been sought about ways of improving its administration and procedures. Individuals taking part in appraisal procedure are encouraged when persistent difficulties are removed, while there is an all-round improvement in morale and teamwork when all-round improved performance begins to influence productivity. In the short term this seldom fails to occur and, over a longer period, can produce more than the National Economic Development Council target of 4 per cent without any increased capital expenditure. This is particularly so where appraisal of performance standards is followed by education and training programmes designed specifically to meet the needs of individual managers. In practice again, the needs of individuals have been followed by much more education and training on the plant than on external courses, and this in itself has led to a greater interest in means of improving productivity. While this systematic approach to management performance is still at an early stage, it offers one of the most fruitful ways of harnessing the practical knowledge and experience of existing managers which has yet been devised. Unfortunately, it requires skilled job analysts and men experienced in promoting in-plant education and training facilities and these are almost as rare as industrial mathematicians.

The main difficulty in introducing such a systematic approach to improved management performance is that it demands great skill in the handling of human relationships. Where the job analyst is a man employed by a company he should be drawn from the higher ranks. Sometimes it is more useful to use an experienced and independent 'outsider' who could profitably be a social research worker or a management consultant. Rosemary Stewart has directed attention to the valuable work which social research workers in industry can do but, surprisingly, she seems unaware of all that enterprising and critical managements are doing to improve their own performances\$. Their efforts would well repay study by those who work in academic institutions. Industry is increasingly learning to make use of techniques being developed in academic institutions-sclection processes, job analysis and the training of skilled operators, executive job grading for salary determination and so on-and many of the practical applications could well be used in the originating centres. The systematic approach to means of improving managerial performance which industry has adopted could profitably be used in other institutions.

* See various publications of the American Management Association and the Society for the Advancement of Management.

†The Management Audit: An Appraisal of Management Methods and Performance. By William P. Leonard. Pp. 238. (Englewood Cliff, N.J. (

$\$$ Harvard Business Review (May-June 1963).

$\S$ The Reality of Management (Heinemann, 1963).

\section{THE MARK OF THE MASTER}

\section{Chromosome Marker}

By K. R. Lewis and B. John. Pp. $\mathrm{x}+489$. (London: J. and A. Churchill, Ltd., 1963.) 65s.

A LTHOUGH it is a quarter of a century since the A publication of the last edition of Darlington's Recent Advances in Cytology, I still find it difficult to read a new book on chromosomes with a mind unbiased by comparison with the Advances. Chromosome Marker is no exception, and in fact the authors almost invite the comparison as they pay just and handsome dedication to their master. It is inevitable therefore that, despite the title which only became meaningful after reading much of the book, I had hoped for the much-needed synthesis of the past twenty-five years work on chromosomes. This is still to be written. Chromosome Marker, for example, does not make the near-synthesis that is now possible of the seemingly conflicting evidence on chromosome structure derived from tritium labelling, enzyme digestion, X-ray breakage and electron microscopy. Nor does it bring together the data on the vexed question of the mechanism of crossing-over. This was not the authors' intention.

The scope of the book, which is divided into four sections, includes a description of the normal behaviour and form of chromosomes in division, chromosome duplication and movement, and the mutational changes which occur in chromosomes. Full and useful accounts are given of the tritium-labelling experiments on duplication, on the action of the centromere in chromosome movement, and the morphological changes in some dipteron chromosomes which are related to cellular activity. Two sections of the book are devoted to types of visible chromosome markers of all kinds and their use in cytological and genetical experiments. A full and useful summary of Riley's work on the genetic control of chromosome pairing in wheat is given. All this is of considerable interest, and is the most valuable part of the book. It should bo particularly valuable in the expanding field of human cytology where much of the plant and animal eytology is now being applied.

The final section of the book on the "Chromosomes in Evolution" invites comparison with the Darlington classic Evolution of Genetic Systems, and it is here that there is some disappointment. This may be because this aspect of genetics is one without a productive methodology. It has to rely largely on ideas and deduction, and therefore a limited advance is inevitable.

The book includes many quotations from the classics; these occupy a prominent place at the beginning of the chapters. It also has a short classification of the plant and animal kingdoms but it does not include a glossary of terms. Most of the scientific terms are explained when they are first used in the text. It is possible to find references in the index to Twain, Mark; Conan Doyle, Sir Arthur; and Carroll, Lewis; but terms such as 'desynapsis' or 'sympatric', used in the text, are not in the index. There is some unnocessary repetition in the book; for example, Chapter 2 begins, "All the characteristics of an organism are the result of interaction between the genotype and the environment. This is the primary postulate of genetics". The next but one chapter begins, "The phenotype is a product of interaction between the genotype and the environment. This is the basic premise of Genetics". Despite these and other small irritations, the book is one that should be read carefully by all who are interested in chromosomes and heredity. D. LEwIS

\section{COMPARATIVE PHILOSOPHY}

Introduction to Comparative Philosophy

By P. T. Raju. Pp. xii +364. (Lincoln: University of Nebraska Press, 1962.) $\$ 7.50$

CTUDENTS in universities and readers in general have $\checkmark$ long been accustomed to books bearing such titles as "Comparative Anatomy" or "Comparative Religion", but "Comparative Philosophy" is novel. For this reason alone, Introduction to Comparative Philosophy is welcome. Moreover, in other ways, too, its appearance is significant. In a world wherein events make themselves felt everywhere with increasing speed, there is an obvious need for a wider understanding both between peoples as such and between individuals of different outlook and of varying 